\title{
Absorption studies after gastrojejunostomy with and without vagotomy
}

\author{
T. J. BUTLER AND R. D. EASTHAM \\ From the Department of Gastroenterology and Pathology, \\ Frenchay Hospital, Bristol
}

SYNOPSIS Faecal fat studies were carried out on patients following vagotomy and gastrojejunostomy (23), gastrojejunostomy alone (32), and vagotomy alone (19). After vagotomy and gastrojejunostomy, there was a significant increase in the faecal fat excretion. The incidence of steatorrhoea was $43 \%$. After vagotomy or gastrojejunostomy alone, there was no significant change in the faecal fat excretion.

Of the various procedures used in the treatment of duodenal ulcer, subtotal gastrectomy has been studied most extensively from the point of view of resulting metabolic disturbance (Butler, 1961; Stammers and Williams, 1963). The alternative procedures, vagotomy combined with gastrojejunostomy, pyloroplasty, or antrectomy, are now coming under the same scrutiny, and it is hoped that the results reported now will add to the accumulating knowledge on this subject.

\section{MATERIAL AND METHODS}

PATIENTS STUDIED The numbers of patients in each group are given in the following table:

\begin{tabular}{llll} 
Operation & Male & Female & Total \\
\hline 1 Vagotomy + gastrojejunostomy & 18 & 5 & 23 \\
2 Gastrojejunostomy alone & 25 & 7 & 32 \\
3 Vagotomy alone & 14 & 5 & 19
\end{tabular}

All the patients had faecal fat studies. In addition, a record was made of the presence or absence of diarrhoea and of weight change since operation.

The first group of patients had tests performed three to five years after operation. The patients with gastrojejunostomy alone had their operations 10 to 32 years previously, and tests were carried out when they were admitted to hospital either for ulcer recurrence (six of 32 patients) or for some unrelated condition (26 of 32). Those who had vagotomy alone had been operated on between 1947 and 1950; of the patients traced, 19 were selected on the basis of complete vagal section confirmed by Hollander's insulin test $(1946,1948)$. The postoperative tests were done during 1952 and 1953. In all cases, the vagotomy was total and not selective.

FAECAL FAT STUdies Faecal fat analyses were carried out while the patients were on an ordinary ward diet containing approximately $70 \mathrm{~g}$. of fat daily (Woodman and Yeoman, 1955). The faecal fat excretion in each patient was measured giving three successive periods of 24 hours. The individual specimens were homogenized and faecal fat was estimated according to the technique of van de Kamer, Huinink, and Weyers (1949).

In normal control patients, the finding with this method of the mean daily fat excretion was 3.91 g. (S.D. $\pm 2.45 \mathrm{~g}$.) of fatty acid. An excess of $6 \mathrm{~g}$. per day was indicative of the presence of steatorrhoea.

HOLLANDER'S INSULIN TEST Following an overnight fast, a Ryle's tube was passed through the nose into the stomach at $8.0 \mathrm{a} . \mathrm{m}$. The position of the tube was checked radiologically. The stomach was emptied, and from 8.30 a.m. two resting, quarter-hourly samples of gastric secretion were collected. At 9.0 a.m. a blood sample was taken for blood sugar estimation. and then 10 to 15 units of regular insulin were administered intravenously. Quarter-hourly samples of gastric secretion were collected for the following one and a half hours. Further blood samples for blood sugar estimations were collected 30 minutes, 45 minutes, and 60 minutes after the insulin administration to ensure a fall in the blood sugar of 45 to $50 \mathrm{mg}$. per $100 \mathrm{ml}$. On completion of the test $50 \mathrm{~g}$. of glucose was given by mouth.

Free acid levels in the gastric samples were determined by titration using thymol blue as an indicator.

\section{RESULTS}

FAECAL FAT AFTER VAGOTOMY AND GASTROJEJUNOSTOMY The pre-operative levels of faecal fat were all within normal limits. Following operation, there was an increase in the faecal fat in all except one patient (no. 10); faecal fat excretion exceeded $6 \mathrm{~g}$. per day in 10 patients (Table I). The incidence of steatorrhoea was $43 \%$.

Comparison of the pre-operative daily mean fat excretion $(2 \cdot 14 \mathrm{~g}$., S.D. $\pm 0 \cdot 59 \mathrm{~g}$.) with the post- 
TABLE I

FAECAL FAT ANALYSES AFTER VAGOTOMY AND GASTROIEIUNOSTOMY

Fatty Acid (g./day)

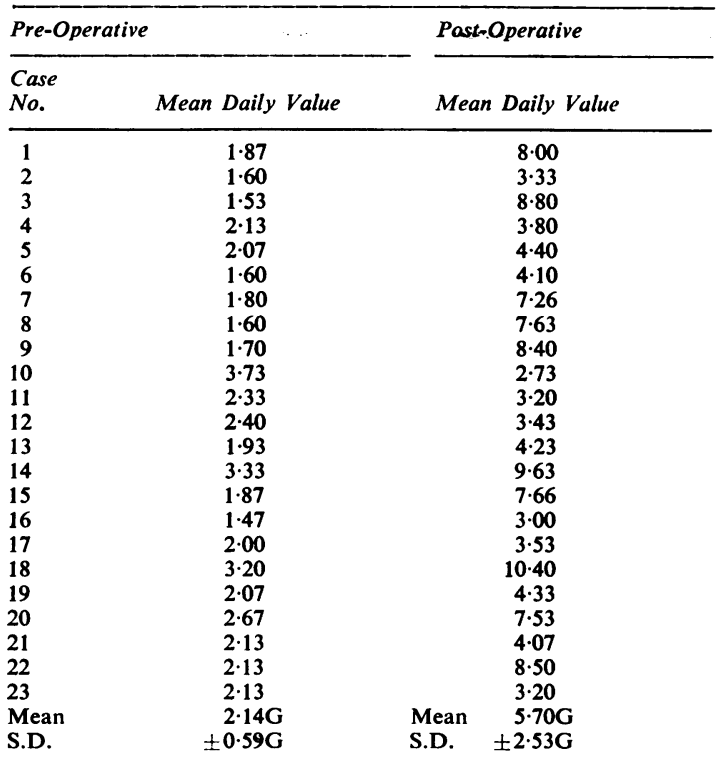

operative mean value $(5 \cdot 70 \mathrm{~g} .$, S.D. $\pm 2 \cdot 52)$ indicates a significant increase $(P=<0.01)$.

Body weight More than half of the group (12 patients) gained weight ( $8 \mathrm{lb}$. or more). In six patients, there was weight loss of the same degree. The weight of the remaining five patients remained unchanged or within $2 \mathrm{lb}$. of their pre-operative weight.

FAECAL FAT AFTER GASTROJEJUNOSTOMY ALONE No pre-operative tests were carried out in this group. All the post-operative faecal fat values were within the normal range (Table II). Comparison of the mean daily excretion $(1.73$ g., S.D. \pm 0.56 g. $)$ with the normal control mean (3.91 g., S.D. \pm 2.45 g.) reveals no significant difference $(P=>0.05)$.

Body weight Apart from the patients who had recurrence of ulcer, all of whom lost weight (six patients), 20 patients in this group gained weight and six remained unchanged.

FAECAL FAT AFTER VAGOTOMY ALONE No preoperative studies were obtained for this group of patients. Post-operatively, in one patient (no. 17), there was steatorrhoea, but the fat excretion in the remaining 18 patients was within normal limits (Table III). The mean daily value for the series $(2.29 \mathrm{~g}$., S.D. $\pm 1.27 \mathrm{~g}$.) is not significantly different from the normal control value $(P=>0 \cdot 05)$.

Body weight Of these patients, 10 gained weight and nine lost weight of the order already mentioned.
TABLE II

FAECAL FAT ANALYSES AFTER GASTROJEJUNOSTOMY ALONE Fatty Acid (g./day)

\begin{tabular}{ll}
\hline Case & Mean Daily Value \\
No. & $2 \cdot 13$ \\
1 & $1 \cdot 46$ \\
2 & $2 \cdot 00$ \\
3 & $2 \cdot 83$ \\
4 & $0 \cdot 87$ \\
5 & $0 \cdot 97$ \\
6 & $2 \cdot 53$ \\
7 & $1 \cdot 70$ \\
8 & $2 \cdot 23$ \\
9 & $2 \cdot 00$ \\
10 & $1 \cdot 86$ \\
11 & $2 \cdot 20$ \\
12 & $1 \cdot 96$ \\
13 & $0 \cdot 76$ \\
14 & $1 \cdot 83$ \\
15 & $1 \cdot 76$ \\
16 & $2 \cdot 83$ \\
17 & $0 \cdot 90$ \\
18 & $1 \cdot 37$ \\
19 & $2 \cdot 40$ \\
20 & 1.63 \\
21 & $1 \cdot 13$ \\
22 & 0.96 \\
23 & $1 \cdot 43$ \\
24 & $1 \cdot 80$ \\
25 & 0.96 \\
26 & $1 \cdot 73$ \\
27 & $2 \cdot 20$ \\
28 & $2 \cdot 00$ \\
29 & $1 \cdot 26$ \\
30 & $1 \cdot 73$ \\
31 & $2 \cdot 00$ \\
32 & $1 \cdot 73 G$ \\
Mean & $\pm 0.56 G$ \\
S.D. & \\
&
\end{tabular}

INCIDENCE OF DIARRHOEA Diarrhoea, defined as 'the too frequent passage of too loose stools', was not present in any patient with gastrojejunostomy alone. Following vagotomy alone, three of the 19 patients $(15.7 \%)$ had diarrhoea, including the one with

\section{TABLE III}

FAECAL FAT ANALYSES AFTER VAGOTOMY ALONE

Fatty Acid (g./day)

\begin{tabular}{lc}
\hline $\begin{array}{l}\text { Case } \\
\text { No. }\end{array}$ & Mean Daily Value \\
\hline 1 & $2 \cdot 63$ \\
2 & $2 \cdot 76$ \\
3 & $2 \cdot 53$ \\
4 & $2 \cdot 76$ \\
5 & $3 \cdot 13$ \\
6 & $2 \cdot 46$ \\
7 & $3 \cdot 46$ \\
8 & $2 \cdot 96$ \\
9 & $2 \cdot 26$ \\
10 & 3.00 \\
11 & $2 \cdot 73$ \\
12 & 3.00 \\
13 & $2 \cdot 66$ \\
14 & $2 \cdot 20$ \\
15 & $2 \cdot 46$ \\
16 & 2.00 \\
17 & 7.93 \\
18 & $2 \cdot 33$ \\
19 & $2 \cdot 26$ \\
Mean & $2 \cdot 92 \mathrm{G}$ \\
S.D. & $\pm 1 \cdot 27 \mathrm{G}$ \\
&
\end{tabular}


steatorrhoea. Following vagotomy and gastrojejunostomy, 10 of the 23 patients had diarrhoea for a few weeks but this persisted in two only $(8 \cdot 7 \%)$. There was no absolute relationship between the presence of steatorrhoea and the incidence of diarrhoea.

\section{DISCUSSION}

In a previous review (Butler, 1961), it was noted that steatorrhoea following gastric operations showed the following features. It occurred rarely following gastrojejunostomy or vagotomy alone. It was rare after the Billroth I operation. It was common after the Polya gastrectomy. It was the rule following total gastrectomy. The addition of vagotomy to gastrectomy or gastrojejunostomy increased the fat content of the stools.

In animals, the basic investigations were done by Welbourn, Hallenbeck, and Bollman (1953) and by Javid (1955). The results reported now confirm some of the findings in man, i.e., the rarity of steatorrhoea after gastrojejunostomy or vagotomy alone and its frequency after vagotomy and gastrojejunostomy. The incidence $(43 \%)$ corresponds to the average incidence after the Polya type of gastrectomy. Kay (1962) noted increased faecal fat after vagotomy and gastrojejunostomy, and Cox (1963) and Cox, Bond, Podmore, and Rose (1964) reported the incidence of steatorrhoea to be $40 \%$. Stammers and Williams (1963) did not find steatorrhoea in four patients studied following vagotomy alone, but indicated that some metabolic disturbance may be found in approximately $50 \%$ of patients following vagotomy and gastrojejunostomy.

It is concluded, therefore, that serious malabsorption does not follow either gastrojejunostomy or vagotomy but may occur quite often when these procedures are combined. It seems that the addition of vagotomy to the short circuit is responsible for the steatorrhoea. Presumably vagotomy interferes in some way with the gastric, intestine, or biliary and pancreatic response to food.

Loss of the gastric reservoir, very important after gastrectomy, is not applicable to the procedure under discussion. Nevertheless, food may reach the jejunum in a state quite unsuitable for enzyme activity to be effective, and reduction of gastric lipolytic activity (Marks, Bank, Krut, and BronteStewart, 1962) may play a part.

The pancreatic response to food is reduced if the meal enters the jejunum directly and this response may be reduced still more by vagotomy (Butler, 1961). Even so, reduced output by the pancreas, although marginal, is probably adequate if the pancreatic excretion has access to food in suitable particulate form in the correct milieu of $p \mathrm{H}$ and bile salt concentration. Inadequate mixing of food with bile and pancreatic secretion is accepted as one of the results of gastrectomy (Brain and Stammers, 1951; Lundh, 1958; Butler, 1961), but it is uncertain whether this occurs following vagotomy and gastrojejunostomy, in which case there may be slower emptying of the stomach.

Altered intestinal motility has also been suggested as a cause. This may be so in those patients with postcibal syndromes, but is unlikely to be the cause of steatorrhoea, for intestinal motility returns to normal very quickly after vagotomy (Ross, Watson, and Kay, 1963). Bacterial colonization of the intestine is another possible factor. Although loss of the gastric acid barrier and altered $p \mathrm{H}$ gradient in the alimentary tract may contribute to this, it is more probable that the growth of organisms is a result of the malabsorption. When established, however, bacterial colonization will certainly aggravate any malabsorption defect. Finally, it is possible for some latent intestinal defect to be made manifest after surgery, but the findings of intestinal biopsy in 10 patients in this series of vagotomy and gastrojejunostomy did not reveal any abnormality.

Post-gastrectomy studies have shown that gastroduodenal continuity gives a better result postoperatively than gastrojejunostomy. Since there is also evidence that the proximal $100 \mathrm{~cm}$. of small intestine is of the greatest importance in absorption (Borgström, Dahlqvist, Lundh, and Sjövall, 1957) the drainage procedure that is used with vagotomy should preserve gastro-duodenal continuity and so keep as much as possible of the vital part of the proximal small intestine in the food pathway. Vagotomy and pyloroplasty would therefore be preferable to vagotomy and gastrojejunostomy. Similarly, if vagotomy and antrectomy is performed, gastro-duodenal continuity should be the aim.

\section{REFERENCES}

Borgström, B., Dahlqvist, A., Lundh, G., and Sjövall, J. (1957). Studies of intestinal digestion and absorption in the human. J. clin. Invest., 36, 1521-1536.

Brain, R. H. F., and Stammers, F. A. R. (1951). Sequelae of radical gastric resections. Lancet, $1,1137-1141$.

Butler, J. T. (1961). The effect of gastrectomy on pancreatic secretion in man. Ann. roy. Coll. Surg. Engl., 29, 300-327.

Cox, A. G. (1963). Intestinal absorption following vagotomy and gastrojejunostomy. Associations of Surgeons Meeting, 1963.

- Bond, M. R., Podmore, D. A., and Rose, D. P. (1964). Aspects of nutrition after vagotomy and gastrojejunostomy. Brit. med. J., 1, 465-469.

Hollander, F. (1946). The insulin test for the presence of intact nerve fibres after vagal operations for peptic ulcer. Gastroenterology 7, 607-614.

- (1948). Laboratory procedures in the study of vagotomy (with particular reference to the insulin test). Ibid., 11, 419-425.

Javid, H. (1955). Nutrition in gastric surgery with particular reference to nitrogen and fat assimilation. Surgery, 38, 641-651. 
Kamer, J. H. van de, Huinink, H. ten B., and Weyers, H. A. (1949). Rapid method of determination of fat in faeces. J. biol. Chem., 177, 347-355.

Kay, A. W. (1962). Gastro-intestinal surgery and human physiology. J. roy. Coll. Surg. Edinb., 7, 275-288.

Lundh, G. (1958). Intestinal digestion and absorption after gastrectomy. Acta. chir. scand., Suppl. 231.

Marks, I. N., Bank, S., Krut, L. H., and Bronte-Stewart, B. (1962). Gastric secretion and alimentary lipaemia in ischaemia heart disease. Lancet, 2, 1068-1072.
Ross, B., Watson, B. W., and Kay, A. W. (1963). Studies on the effect of vagotomy on small intestinal motility using radio-telemetering capsule. Gut, 4, 77-81.

Stammers, F. A. R., and Williams, J. A. (1963). Partial Gastrectomy. Butterworths, London.

Welbourn, R. B., Hallenbeck, G. A., and Bollman, J. L. (1953). Effect of gastric operations on loss of fecal fat in the dog. Gastroenterology, 23, 441-451.

Woodman, D., and Yeoman, W. B. (1955). A simplified method of investigating steatorrhoea. J. clin. Path., 8, 79-80.

\section{}

